\title{
Molecular Identification and Phylogenetic Analysis of Heterakis dispar Isolated from Geese
}

\author{
Kamila Bobrek ${ }^{1}$ · Joanna Hildebrand ${ }^{2}$. Joanna Urbanowicz ${ }^{1}$. Andrzej Gaweł ${ }^{1}$
}

Received: 19 November 2018 / Accepted: 11 July 2019 / Published online: 11 September 2019

(c) The Author(s) 2019

\begin{abstract}
Purpose Heterakidosis is a common parasitic infection caused in domestic birds by Heterakis species: Heterakis gallinarum, $H$. isolonche, and H. dispar. Among them, the best described species is H. gallinarum, noted mainly in gallinaceous birds. In waterfowl, $H$. dispar is the predominant species. The variations in morphology and host specificity qualify $H$. dispar as a different species, but the phylogenetic relationships between heterakids were unclear for a long time, because of a lack of H. dispar sequences.

Methods The authors provided the molecular data for $H$. dispar and analyzed the obtained sequences of the partial $18 \mathrm{~S}$ rRNA gene and region ITS1-5.8SrRNA-ITS2 with the homological sequences.

Results The 18S rRNA PCR product of $H$. dispar was about $800 \mathrm{bp}$, and the ITS-5.8S-ITS2 PCR product was about 920 bp, noticeably smaller size compared to $H$. gallinarum product. The BLAST analysis of $H$. dispar $18 \mathrm{~S}$ sequence showed a 99\% similarity with the sequences of Heterakis gallinarum and Ascaridia galli, $98 \%$ with A. nymphii, but only $94 \%$ with the sequence of Heterakis sp. Our ITS sequence of H. dispar was almost identical to the H. isolonche isolate, there is only one nucleotide of difference among the 943 sites analyzed. It also showed a lower similarity to the ITS sequences of $\mathrm{H}$. gallinarum (88\%), H. spumosa (87\%), and H. dahomensis (87\%).

Conclusions In our phylogenetic analysis, it is the first attempt at the reconstruction of relationships within this superfamily Heterakoidea based on 18S rDNA and ITS region.
\end{abstract}

Keywords Heterakis dispar · Parasite · 18S rRNA · ITS1-5.8rRNA-ITS2 · Geese

\section{Abbreviation \\ ITS Internal transcribed spacers}

\section{Introduction}

Heterakidosis is a common parasitic infection in birds but rarely in rodents. It is caused by the Heterakis species (Nematoda, Secernentea, Ascaridida, Heterakoidea, and Heterakoidea). These nematodes infect the ceca of numerous

Kamila Bobrek

kamila.bobrek@upwr.edu.pl

1 Department of Epizootiology with Clinic of Birds and Exotic Animals, Faculty of Veterinary Medicine, Wrocław University of Environmental and Life Sciences, pl. Grunwaldzki 45, 50-366 Wrocław, Poland

2 Department of Parasitology, Institute of Genetics and Microbiology, University of Wrocław, Przybyszewskiego 63/77, 51-148 Wrocław, Poland species of wild and domestic birds [1, 2]. In domestic birds, three species of Heterakis, differentiated mostly by the morphological characters of males are noted and described: Heterakis gallinarum (Schrank, 1788) noted mainly in gallinaceous birds such as chicken, turkey, guinea fowl, partridge, quail, but also in waterfowl. Heterakis isolonche (Linstow, 1906) is common in pheasants, but has also been recovered from ducks, turkey, grouse, prairie chicken, and quail, and Heterakis dispar (Schrank, 1790), reported in geese and ducks [3-8]. The life cycle of heterakids is direct: eggs are passed in feces and embryonate in the environment within 2 weeks, the infective eggs are ingested by the host directly or birds can be infected by eating earthworms, which are indicated as a paratenic host or mechanical transport host $[9,10]$. The infection occurs mostly in poultry kept on litter or that has come in contact with soil in pastures $[11,12]$.

Among bird's Heterakis species, the best described is $H$. gallinarum. This species is able to infect waterfowl and gallinaceous birds and causes an inflammation of ceca resulting in wall thickness. H. gallinarum might also be a vector of 
Histomonas meleagridis, a protozoan which is an etiological agent of histomoniasis - a fatal disease in turkeys and hens. The body length of an $H$. gallinarum female is $10-15 \mathrm{~mm}$ approximately and the male $7-13 \mathrm{~mm}$. The male has 12 pairs of tail papillae and its spicules are of various lengths-the left spicule is 3.5 times longer than the right one [5, 13].

Heterakis isolonche is similar in morphology to H. gallinarum (females measure 9-12 mm and males 6-15 mm), but the spicules of males are long and of equal length. The species invasions are connected with high mortality, especially in pheasants in which the nodular lesions are observed [14].

Heterakis dispar is the biggest species of bird's heterakids (female 16-23 mm, male 7-18 $\mathrm{mm}$ ), but it is considered less pathogenic than $H$. gallinarum and $H$. isolonche. The characteristic features of the male are 13 pairs of tail papillae and short, equal-length spicules.

Not much information is available about $H$. dispar including epizootiology and pathogenicity $[1,5,13]$. Because of differences in morphology and host specificity $H$. dispar was qualified as a different species than $H$. gallinarum and $H$. isolonche, but the phylogenetic relationships were unclear for a long time, because of a lack of $H$. dispar sequences.

The authors provided the molecular data for $H$. dispar and analyzed the obtained sequences of the partial 18S rRNA gene and region ITS1-5.8SrRNA-ITS2 with the homological sequences available in the GenBank database, to complete the phylogenetic relationship within the Heterakis genus.

\section{Materials and Methods}

\section{Necropsy and Parasites}

Adult nematodes were collected from the ceca of naturally infected geese which were delivered to the Department of Epizootiology and Clinic of Birds and Exotic Animals, Faculty of Veterinary Medicine in Wrocław for a necropsy and diagnostic analysis. Of the four geese, three of them were infected with Heterakis sp.

The nematodes were washed in physiological saline, counted, and identified preliminarily by sex and species based on the morphological characters of males including the size of the parasite, the length of the spicules and the number of caudal papillae $[5,9]$. For the DNA extraction, five randomly selected parasites from each goose were chosen.

\section{DNA Extraction and PCR Reactions}

The DNA was extracted using a GeneMATRIX Tissue DNA Purification Kit (EURx, Gdansk, Poland) in accordance with the manufacturer's instructions and stored at $-20{ }^{\circ} \mathrm{C}$ until used.
For 18S rRNA and ITS-5.8rRNA-ITS2 region, PCR reactions were performed using a $12.5 \mu \mathrm{l} 2 \mathrm{xPCR}$ Master Mix Plus (A\&A Biotechnology, Gdynia, Poland); $0.2 \mu \mathrm{l}$ of each primer, i.e., Nem 18S-F1 with Nem 18S-R1 for 18S rRNA amplification and Primer 2 forward with Primer 2 reverse for ITS-5.8rRNA-ITS2 fragment [15, 16]; $2 \mu \mathrm{LNA}$ and RNAse free water (A\&A Biotechnology, Gdynia, Poland) for a total volume $25 \mu \mathrm{l}$.

The PCR conditions for the amplification of 18S rRNA were as follows: initial denaturation at $94{ }^{\circ} \mathrm{C}$ for $3 \mathrm{~min}, 35$ cycles of denaturation at $90^{\circ} \mathrm{C}$ for $30 \mathrm{~s}$, primer annealing at $55^{\circ} \mathrm{C}$ for $1 \mathrm{~min}$, and extension at $72{ }^{\circ} \mathrm{C}$ for $1.5 \mathrm{~min}$. The final extension was at $72{ }^{\circ} \mathrm{C}$ for $10 \mathrm{~min}$ [17]. The PCR cycling parameters for the ITS-5.8rRNA-ITS2 amplification consisted of an initial denaturation at $95^{\circ} \mathrm{C}$ for $10 \mathrm{~min}$, followed by 35 cycles of denaturation at $95^{\circ} \mathrm{C}$ for $30 \mathrm{~s}$, primer annealing at $67.6{ }^{\circ} \mathrm{C}$ for $1 \mathrm{~min}$, and extension at $72{ }^{\circ} \mathrm{C}$ for $1 \mathrm{~min}$. The final extension was at $72{ }^{\circ} \mathrm{C}$ for $10 \mathrm{~min}$. [16].

PCR products from both reactions were visualized with 2\% agarose gel containing a Midori Green advance DNA strain (NIPPON Genetics Europe GmbH, Dueren, Germany) under UV light. Positive products were isolated from agarose gel using a Gel Out Concentrator Kit (A\&A Biotechnology, Gdynia, Poland) and were subsequently sent to Macrogen (Amsterdam, Netherlands) for sequencing.

\section{Sequencing and Phylogenetic Analysis}

The nucleotide sequences obtained in this study were edited; chromatograms were inspected visually and then aligned with similar sequences available in the National Center for Biotechnology Information (NCBI) GenBank database using CLUSTALW in MEGA7 package [18]. Identical 18S rRNA and ITS region sequences were observed from all nematode specimens. The received sequences of $H$. dispar have been deposited in the EMBL database under accession numbers MG763171 (18S rRNA) and MF319969 (ITS1-5.8SrRNA-ITS2).

Phylogenetic analyses were performed based on partial 18S rDNA gene and ITS region of the newly obtained sequences and selected sequences of the representatives of the superfamily Heterakoidea and genus Heterakis available in GenBank. The sequences were aligned using ClustalW multiple alignment implemented in Mega7 [18]. Both alignments were trimmed to the length of the shortest sequence. Phylogenetic analyses were conducted using Bayesian inference (BI) as implemented in MrBayes ver. 3.2.6 software [19]. The general time reversible model with estimates of invariant sites and gamma distributed among-site variation $(\mathrm{GTR}+\mathrm{I}+\mathrm{G})$ was identified as the best-fitting nucleotide substitution model for both analyses using jModelTest 2 software [20]. Markov chain Monte Carlo (MCMC) chains 
were run for 2,000,000 generations, log-likelihood scores were plotted, and the final $75 \%$ of trees were used to produce the consensus trees. The trees were visualized in FigTree ver. 1.4.3 software [21].

\section{Results}

\section{Necropsy Results and Parasites' Identification}

The necropsied geese died because of peritonitis caused by E. coli. The nematodes were found in ceca, but no lesions of the cecal wall were observed. 15, 20, and 37 Heterakis specimens were obtained from three geese. Fortyfive females and twenty-seven males were collected. All
Fig. 1 a Ventral side of tail end of Heterakis dispar male. b Lateral side of tail end of Heterakis dispar male. 1-Preanal sucker, 2-spicules, 3-preanal pairs of papillae, 4-adanal pairs of papillae, and 5-postanal papillae
A

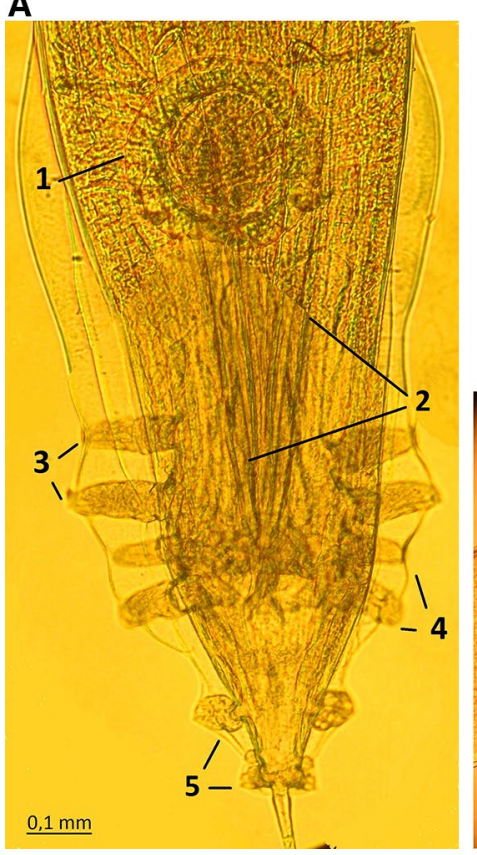

B

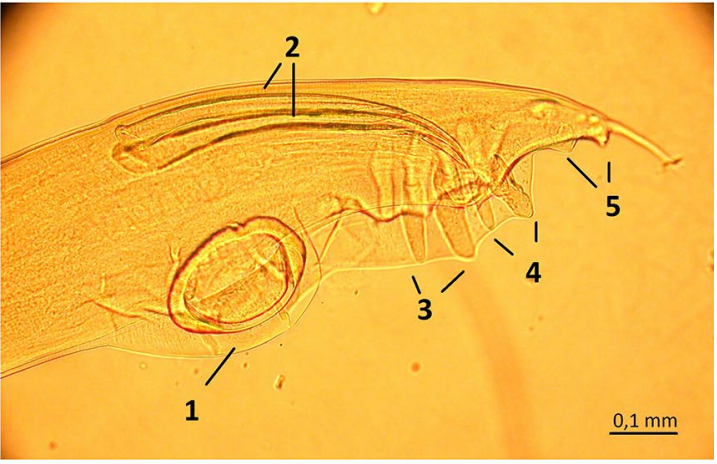

Table 1 Morphometric characters of Heterakis dispar males

\begin{tabular}{|c|c|c|c|}
\hline \multirow[t]{2}{*}{ Characters $(\mu \mathrm{m})$} & \multicolumn{2}{|l|}{ Data } & \multirow{2}{*}{$\begin{array}{l}\text { References } \\
\text { Size or } x \pm \mathrm{SD}\end{array}$} \\
\hline & Size & $x \pm \mathrm{SD}$ & \\
\hline Length of the body & $8175-11,625$ & $9696.4 \pm 946.4$ & $\begin{array}{l}1210-1480[5] \\
10,000-15,000[9] \\
13,360 \pm 980[13]\end{array}$ \\
\hline Width of the body at bulbus & $320-350$ & $328.6 \pm 7.3$ & $\begin{array}{l}350-380[9] \\
410 \pm 30[13]\end{array}$ \\
\hline Sucker diameter & $180-205$ & $195.0 \pm 6.3$ & $\begin{array}{l}183-256[5] \\
200[9] \\
149.58 \pm 5.03[13]\end{array}$ \\
\hline Distance from preanal sucker to the tail end & $480-635$ & $545.7 \pm 31.8$ & $\begin{array}{l}274-518[5] \\
570 \pm 60[13]\end{array}$ \\
\hline Length of left spicule & $400-460$ & $434.3 \pm 19.3$ & $\begin{array}{l}550-700[5] \\
530-560[9] \\
390 \pm 20[13]\end{array}$ \\
\hline Width of left spicule in the proximal end & $26-35$ & $29.1 \pm 1.9$ & $29.33 \pm 1.01[13]$ \\
\hline Length of right spicule & $410-410$ & $437.1 \pm 16.6$ & $\begin{array}{l}610-700[5] \\
530-560[9] \\
400 \pm 10[13]\end{array}$ \\
\hline Width of right spicule in the proximal end & $26-30$ & $28.8 \pm 1.2$ & $30.30 \pm 1.34[13]$ \\
\hline
\end{tabular}


analyzed males isolated from the geese were characterized by short, equal-length spicule and 13 pairs of tail papillae-4 preanal, 4 adanal, and 5 postanal pairs what is typical for Heterakis dispar (Fig. 1a, b). The rest of

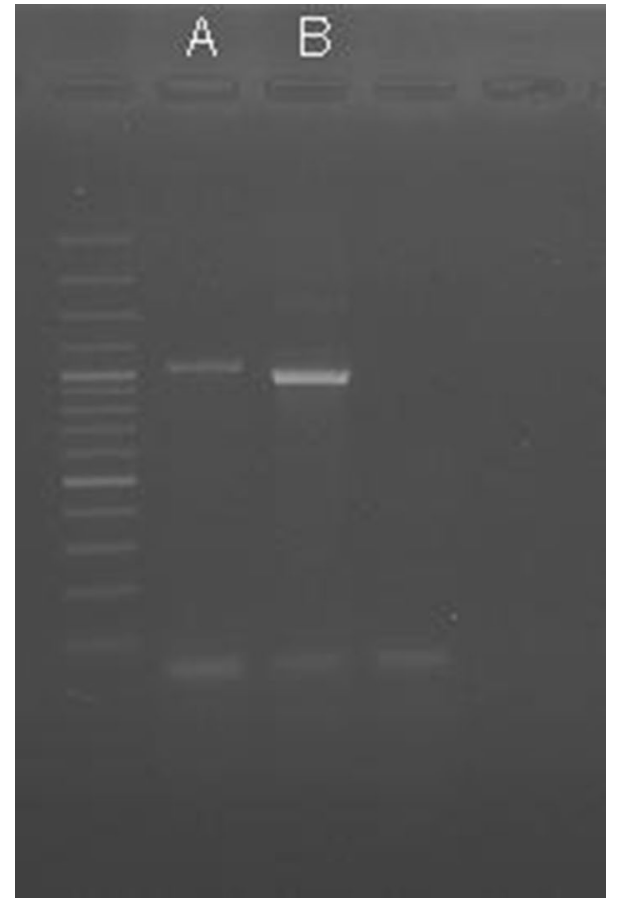

Fig. 2 The PCR products of $H$. gallinarum (a) and $H$. dispar (b) with Thermo Scientific ${ }^{\mathrm{TM}}{ }^{\mathrm{GeneR}}$ Ruler ${ }^{\mathrm{TM}} 100$ bp plus DNA ladder morphometrical feature of males listed in the Table 1 also corresponded with the description of $H$. dispar provided by Madsen [5] and Yevstafyeva et al. [13].

\section{PCR Results and Molecular Analysis}

The 18S rRNA PCR product of $H$. dispar was about $800 \mathrm{bp}$ and was similar to the $H$. gallinarum product. The ITS-5.8SITS2 PCR product of $H$. dispar has a noticeably smaller size about $920 \mathrm{bp}$ comparing to $\sim 1100 \mathrm{bp} \mathrm{H}$. gallinarum product (Fig. 2). The PCR reaction amplifying the ITS region turned out to be a good tool for differentiation $H$. gallinarum and H. dispar.

\section{The Phylogenetic Analysis}

The provided comparative analysis of the newly obtained $H$. dispar sequences with the homological sequences available in the GenBank showed the molecular differentiation of representatives of the Heterakis genus recorded in geese. However, because of the lack of an 18S rRNA sequence of $H$. isolonche in the GenBank, we were able to compare only $H$. dispar with $H$. gallinarum on both genes. In the $18 \mathrm{~S}$ rRNA sequence, seven substitutions-five transitions and two transversions-were observed. The substitutions were noted in the 468, 476, 485, 504, 516, 517, and 634 positions of the analyzed sequence (Fig. 3). The variety in the partial 18S rRNA gene between $H$. dispar and $H$. gallinarum is less than $1 \%$.
MG763171 Heterakis dispar DQ503462. 1Heterakis gallinarum

MG763171 Heterakis dispar DQ503462.1Heterakis gallinarum

MG763171 Heterakis dispar DQ503462. 1Heterakis gallinarum

MG763171 Heterakis dispar DQ503462.1Heterakis gallinarum

MG763171 Heterakis dispar DQ503462.1Heterakis gallinarum

MG763171 Heterakis dispar DQ503462. 1Heterakis gallinarum

MG763171 Heterakis dispar DQ503462. 1Heterakis gallinarum

MG763171 Heterakis dispar DQ503462. 1Heterakis gallinarum

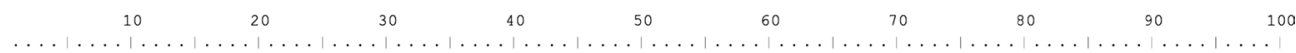
CCAAAGCTCCGATTTTGACGAGCGCATCTATTAGATTAAAACCAATCAGGTTTCGGCCTGTTTATTGGTGACTCTGAATAGCTTAGCTGATCGCATGGTC $\begin{array}{llllllllll}110 & 120 & 130 & 140 & 150 & 160 & 170 & 180 & 190 & 200\end{array}$ TTGAACCGGCGACGTGTCTATCAAGTGTCTGCCTTATCAACTTTCGATGGTAGTTTAACTGCCTACCATGGTCGTAACGGGTAACGGAGAATAAGGGTTC

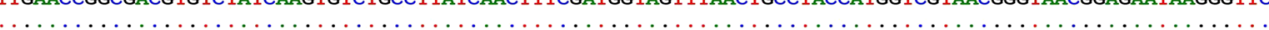
$\begin{array}{rrrrrrrrr}210 & 220 & 230 & 240 & 250 & 260 & 270 & 280 & 290\end{array}$ GACTCCGGAGAGGGAGCCTTAAAAACGGCTACCACATCCAAGGAAGGCAGCAGGCGCGCAAATTACCCACTCTCAGCATGAGGAGGTAGTGACGAAAAAT

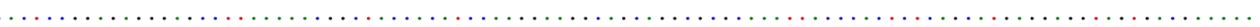
$\begin{array}{lllllllll}310 & 320 & 330 & 340 & 350 & 360 & 370 & 380 & 390\end{array}$ AACAAGACCGTTCTCTATGAGGCCGGTTATTGGAATGAGTACAATTTAAATCCGTTAACGAGGATCTATGAGAGGGCAAGTCTGGTGCCAGCAGCCGCGG

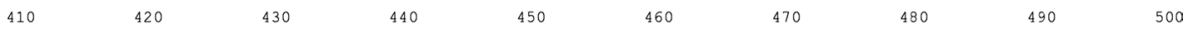
TAATTCCAGC TCTCAAAGTGTATATCGTCATTGCTGCGGTTAAAAAGCTCGTAGTTTGATATGCGCTGCAGGATTCGGTCCGCCTATTGGGCGTGAACTG

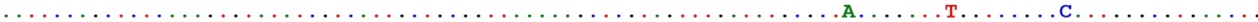

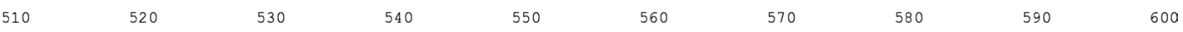
AACCCCTGGGCTAGTATTGTTGGTTTTCCTTACGTTACCTTAATCGGTTGCGTAGGGTGACTAACGAGTTTACTTTGAAAAAATTAGAGTGCTTAACGCG AACCCCTGGGCTAGTATTGTTGGTTTCCTTACGTTACCTTAATCGGTGCGTAGGGTGACTAACGAGTTTACTTTGAAAAAATTAGAGTGCTTAACGCG $\begin{array}{rrrrrrrrr}610 & 620 & 630 & 640 & 650 & 660 & 670 & 680 & 690\end{array}$ GGCATATGCCTGAATATTCGTGCATGGAATAATGGAATAGGATCTCGGTTCTATTTTGTTGGTTTTCTGATCTGAGATAATGGTTAAGAGGGACAGACGG

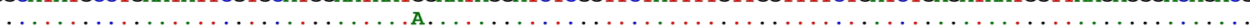
$710 \quad 720 \quad 730 \quad 740 \quad 750 \quad 760$ GGGCATTCGTATCGCTTCGTGAGAGGTGAAATTCTTGGACCGTAGCGAGACGCCCGACTGCGAAA

Fig. 3 A comparison of $18 \mathrm{~S}$ rRNA fragment of $H$. dispar and H. gallinarum 
The comparison of the ITS region of the analyzed $H$. dispar to the H. gallinarum and $H$. isolonche sequences (943 bp) is shown in Fig. 5. The sequences of H. beramparie because of their shorter length were excluded from this analysis. In the conservative, protein coding 5.8S rRNA sequence, five substitutions in the 430, 455, 467, 524, and 561 positions, four transitions, and one transversion in the $H$. dispar sequence occurred according to the $H$. gallinarum sequence (Fig. 4). In the analyzed ITS1 region, there were 68 or 69 substitutions, and in the ITS2 region, 155 substitutions between $H$. dispar and $H$. gallinarum were noted. This yields a $24.2 \%$ variety in the ITS1-5.8S-ITS2 region sequence between those two species. Simultaneously, we have only noted one nucleotide substitution between the $H$. dispar and $H$. isolonche. This transversion in position 44 is in the ITS1 fragment.

The BLAST analysis of $H$. dispar $18 \mathrm{~S}$ sequence (MG763171) showed a 99\% similarity with the sequences of H. gallinarum (DQ503462) and Ascaridia galli (EF180058), 98\% with A. nymphii (LC057210), but only $94 \%$ with the sequence of Heterakis sp. (AF083003). Our ITS sequence of $H$. dispar (MF319969) was almost identical to the $H$. isolonche isolate (KM212953); there is only one nucleotide of difference among the 943 sites analyzed. It also showed a lower similarity to the ITS sequences of $H$. gallinarum (88\%, KT310157), H. beramporia (87\%, KU529974.1), H. spumosa (87\%, JX845278), and H. dahomensis (87\%, JX845277). The differences between the ITS sequences of the $H$. dispar and Ascaridia species were larger. According to the BLAST analysis, A. galli KX683286 and A. galli KY789470 are similar to H. dispar in $80 \%$ (560 of the positions analyzed).

In an attempt to create phylogenetic relationships of $H$. dispar, we performed the Bayesian inference (BI) analysis based on a partial 18S rRNA gene and ITS1-5.8S2-ITS2 region of representatives of Heterakis species and some related species from Heterakoidea. Unfortunately, our choice of molecular target was limited by sequences currently available in the GenBank. At least, the phylogenetic analysis involved 10 nucleotide sequences and a total of 1029

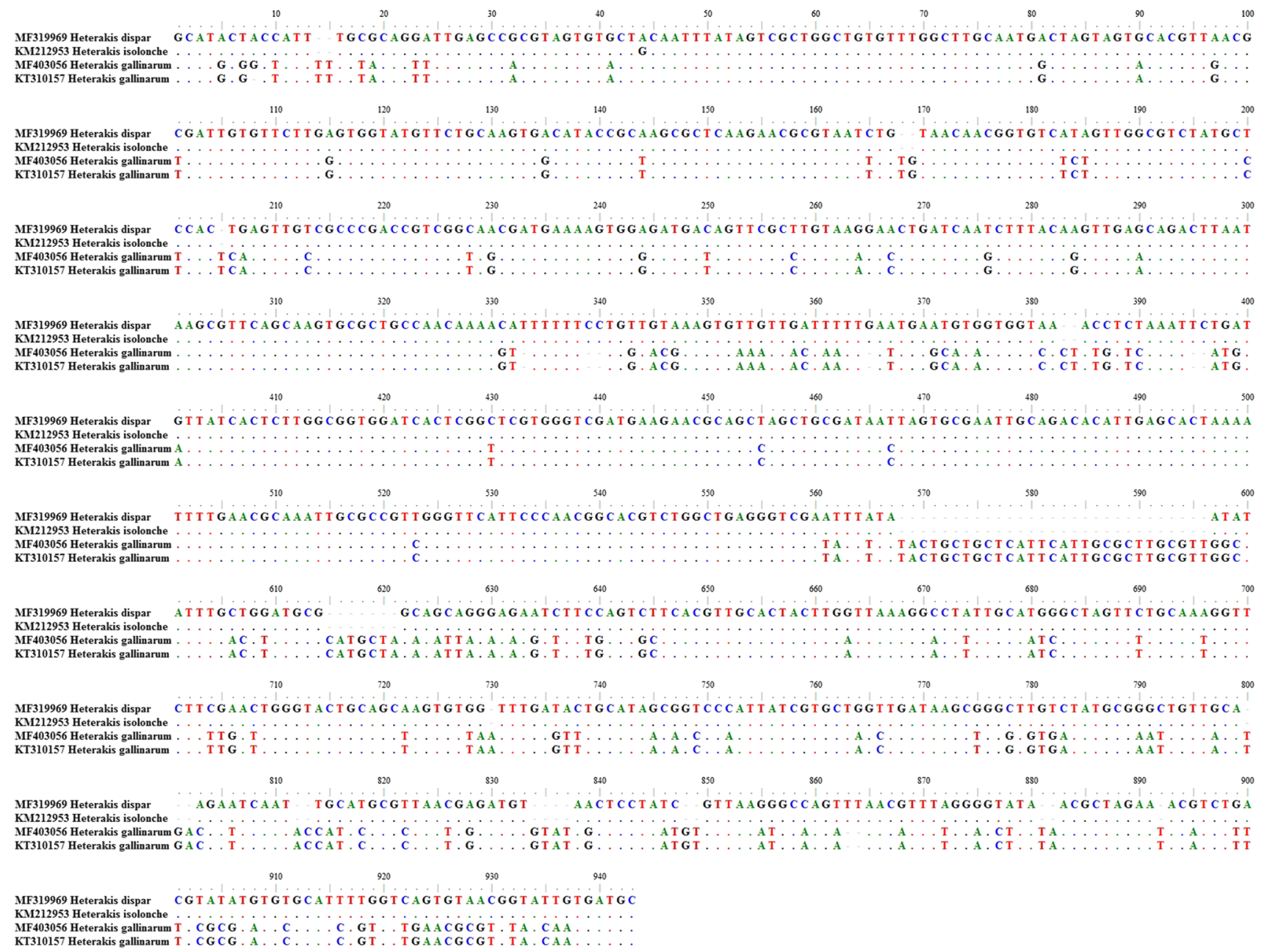

Fig. 4 A comparison of ITS1-5.8S-ITS2 fragment of H. dispar, H. gallinarum, and H. isolonche 
positions in the final dataset in ITS case, 8 sequences, and a total of 774 positions in the dataset in $18 \mathrm{~S}$ case. The analysis of $18 \mathrm{~S}$ rRNA generated a phylogenetic tree with topologies supported by differential (65-99) values. The tree revealed well-supported clade of bird's parasites, i.e., Heterakis sp. and Ascaridia sp., with $97 \%$ branch support; however, not all members of Heterakis were clustered in the same group, but together with other representatives of superfamily, i.e., Aspidodera sp. and Strongyluris sp. (Fig. 5). The phylogenetic tree generated based on ITS region formed two clearly separated clades: one included the Heterakis species from birds (74\% branch support) and the second well-supported $(100 \%)$ contained mammalian heterakids (Fig. 6).

\section{Discussion}

The morphology and ecology of the parasite have traditionally provided the basis for nematode taxonomy. Recent analyses of the rRNA gene sequences have allowed for a revision of nematode phylogeny and taxonomy [16, 22-24]. A group of genes, which encode three subunit rRNA (18S, 5.8S, and 28S) with external and internal sequences separating (ITS and ETS), are the most frequently used area for research. The differences in morphology between $H$. gallinarum, $H$. isolonche, and $H$. dispar noticed under the microscope [5, 9] showed that they are different species. Veterinarians who treat poultry flocks have no need to classify the cecal nematodes, because the antihelminth treatment does not depend on the Heterakis species. The flock treatment recommendations are made during the birds' necropsy, and future analysis are not necessary for the owner. In our opinion, it might be one of the reasons, why there are not many sequences of nematodes isolated from poultry, including Heterakis spp. It is the first molecular analysis of $H$. dispar according to other nematodes. In our study, the structures typical for $H$. dispar were observed and the genetic analysis of the $18 \mathrm{~S}$ rRNA gene and ITS1-5.8S-ITS2 region confirmed that this species differ from $H$. gallinarum. Ribas et al. [25] compared two mammal Heterakis-H. spumosa and H. dahomensis-define those species with an avarage of estimate of evolutionary divergence of $3.12 \pm 0.83$ base of differences per site. In our study, the analyzed ITS1-5.8S-ITS2 H. dispar sequence varied $25.5 \%$ from the $H$. gallinarum. It is difficult to relate to data of $H$. isolonche, because there is no $18 \mathrm{~S}$ rRNA sequence and there is only one ITS1-5.8SITS2 sequence of this species, and no publication that could provide more details about this isolate. However, considering our and Ribas' molecular results and with reference to the morphological data of Heterakis species, it was to be expected that differences between $H$. dispar and $H$. isolonche will be significant. In our opinion, the high similarity

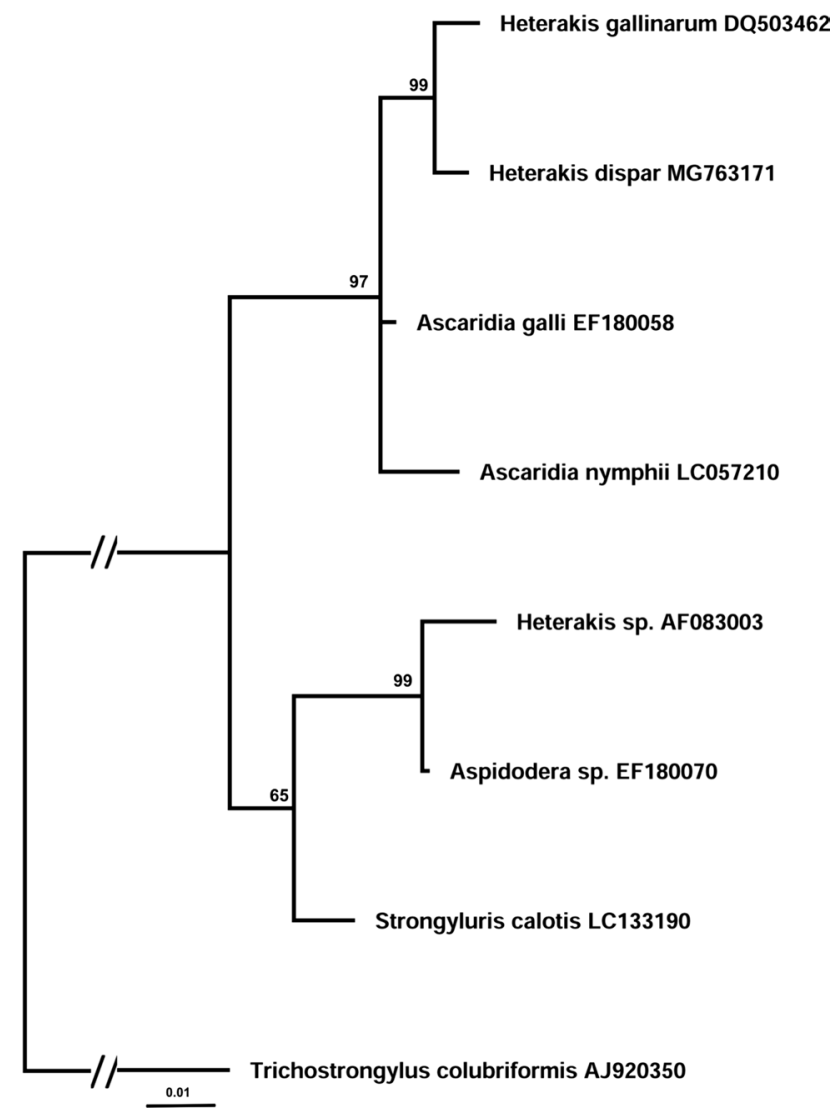

Fig. 5 Phylogenetic interrelationships among representatives of Heterakoidea superfamily based on Bayesian analysis of partial sequences of the $18 \mathrm{~S}$ rDNA gene. The scale bar indicates the number of substitutions per site. Trichostrongylus colubriformis was used as an outgroup

of ITS sequences of $H$. dispar and $H$. isolonche could suggest that there has been a mistake in the identification of the specimen from the China Rhine goose (GenBank accession number KM212953).

Our phylogenetic analysis is the first attempt at the reconstruction of relationships within this superfamily Heterakoidea, but has not been completed, because is still limited to a few representatives of this group of nematodes and fragmentary molecular data. Thus, our study complements the analysis provided by Nadler et al. [26].

The phylogenetic tree based on the ITS1-5.8S-ITS2 rRNA region shows a close relationship between heterakids parasitizing poultry, which are grouped into separated clade, and between nematodes isolated from rodents forming second clade. This result does not confirm former taxonomy of Heterakis based on morphometric features, e.g., this one was proposed by Skrjabin [27], who divided this genus according to the length of its spicules (equal vs. unequal) into Ganguleterakis and Heterakis. 
Fig. 6 Bayesian analysis of ITS1-5.8S rDNA-ITS2 region sequences of Heterakis spp. constructed using MrBayes. The scale bar indicates the number of substitutions per site. Toxocara cati was used as an outgroup

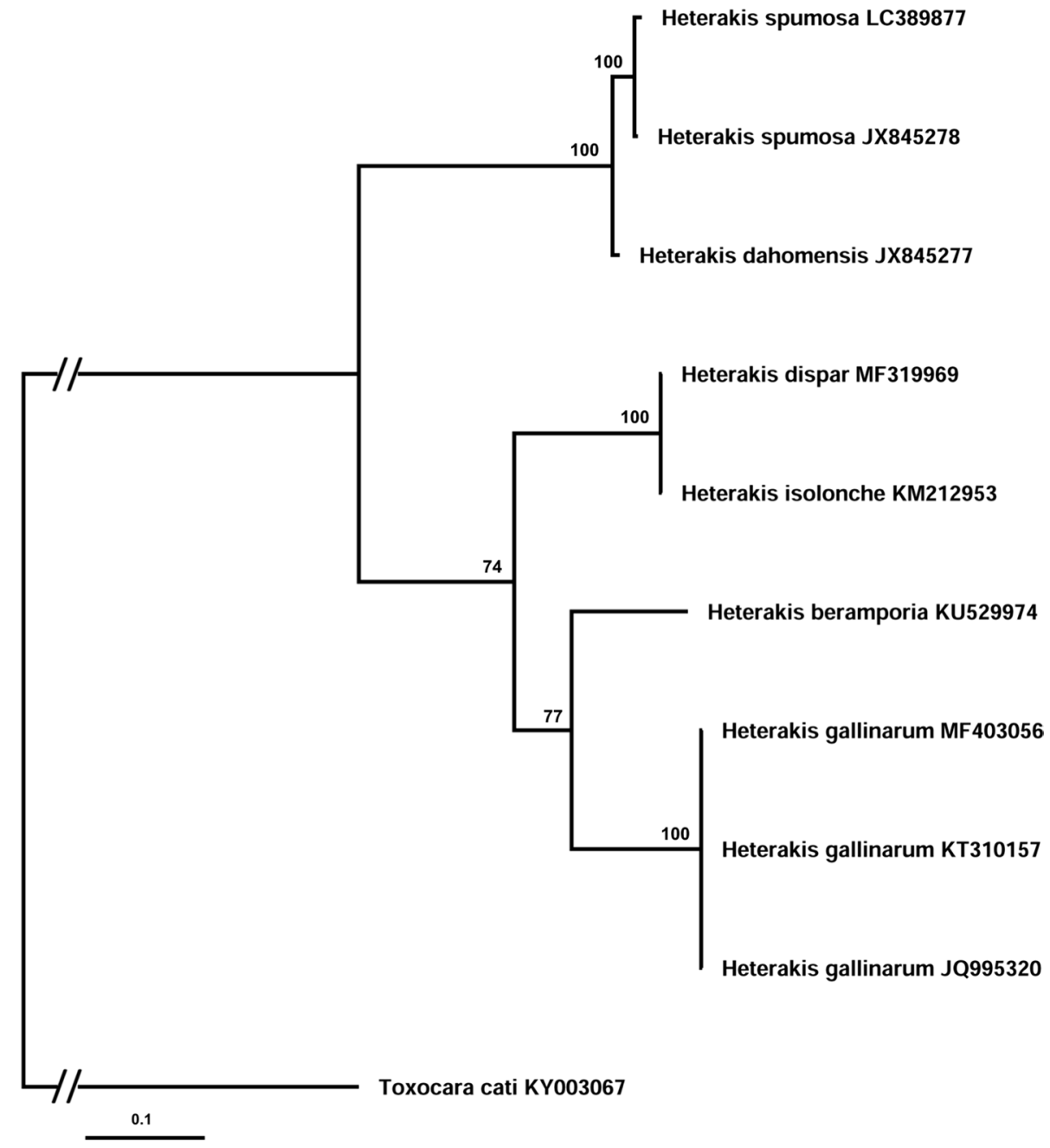

\section{Conclusion}

In this study, we analyzed the Heterakis dispar sequences, and provide a reconstruction of the relationships within the Heterakoidea family. The phylogenetic tree based on ITS15.8S-ITS2 rRNA sequences confirms a close relationship between poultry heterakids, which forms a separated clade on it. Further investigation looking at wider array of heterakids samples may shed light on the diversity within the genus and relationships within Heterakoidea superfamily.

Acknowledgements Research was supported by Wrocław Center of Biotechnology, programme The Leading National Research Center (KNOW) for years 2014-2018.

Open Access This article is distributed under the terms of the Creative Commons Attribution 4.0 International License (http://creativeco mmons.org/licenses/by/4.0/), which permits unrestricted use, distribution, and reproduction in any medium, provided you give appropriate credit to the original author(s) and the source, provide a link to the Creative Commons license, and indicate if changes were made.

\section{References}

1. Amundson CL, Traub NJ, Smith-Herron AJ, Flint PL (2016) Helminth community structure in two species of arctic-breeding waterfowl. Int J Parasitol Parasites Wildl 5:263-272

2. Zuchowska E (1997) Helminth fauna Anseriformes (Aves) in the Lodz Zoological Garden. Wiad Parazytol 43:213-221

3. Hoque MA, Skerratt LF, Rahman MA, Alim MA, Grace D, Gummow B, Rabiul Alam Beg AB, Debnath NC (2011) Monitoring the health and production of household jinding ducks on Hatia Island of Bangladesh. Trop Anim Health Pro 43:431-440

4. Kornaś S, Basiaga M, Kowal J, Nosal P, Wierzbowska I, Kapkowska E (2015) Zatorska goose-a subject of parasitological research. Ann Parasitol 61:253-256

5. Madsen H (1950) Studies on species of Heterakis (nematodes) in birds. Dan Rev Game Biol 1:1-43

6. Park SI, Shin SS (2010) Concurrent Capillaria and Heterakis infections in zoo rock partridges, Alectoris graeca. Korean J Parasitol 48:253-257

7. Shutler D, Alisauskas RT, Daniel McLaughlin J (2012) Associations between body composition and helminths of lesser snow geese during winter and spring migration. Int $\mathbf{J}$ Parasitol 42:755-760

8. Wang XQ, Lin RQ, Gao Y, Cheng T, Zou SS, He Y, Li GY, Weng YB, Zhu XQ (2012) Prevalence of intestinal helminths 
in domestic goose (Anser domesticus) in Qingyuan, Guangdong Province, China. Afr J Microbiol Res 6:6843-6846

9. Czapliński B (1960) Robaczyce drobiu i ich zwalczanie. Państwowe Wydawnictwo Naukowe, Warszawa

10. Permin A, Hansen JW (1998) Heterakis spp. In: FAO animal health manual. Epidemiology, diagnosis and control of poultry parasites. Food and Agriculture Organization of the United Nations, Rome

11. Phiri IK, Phiri AM, Ziela M, Chota A, Masuku M, Monrad J (2007) Prevalence and distribution of gastrointestinal helminths and their effects on weight gain in free-range chickens in Central Zambia. Trop Anim Health Pro 39:309-315

12. Kaufmann F, Daş G, Sohnrey B, Gauly M (2011) Helminth infections in laying hens kept in organic free range systems in Germany. Livest Sci 141:182-187

13. Yevstafyeva VA, Melnychuk VV, Nikiforova OV, Suprunenko KV, Korchan LN, Lokes-Krupka TP, Nehrebetskyi IS, Korchan NI (2018) Comparative morphology and biology of nematodes of genus Heterakis (Nematoda, Heterakoidea), parasites of the domestic goose (Anser anser) in Ukraine. Regul Mech Biosyst 9:229-236

14. Halajian A, Kinsella JM, Mortazavi P, Abedi M (2013) The first report of morbidity and mortality in golden pheasant, Chrysolophus pictus, due to a mixed infection of Heterakis gallinarum and H. isolonche in Iran. Turk J Vet Anim Sci 37:611-614

15. Floyd R, Rogers A, Lambshead J, Smith C (2005) Nematode specific PCR primers for the $18 \mathrm{~S}$ small subunit rRNA gene. Mol Ecol Notes 5:611-612

16. Bazh EK (2013) Molecular characterization of Ascaridia galli infecting native chickens in Egypt. Parasitol Res 112:3223-3227

17. Hassani-Kakhki M, Karimi J, Shokoohi E (2013) Molecular and morphological characterization of Pristionchus pacificus (Nematoda Rhabditida: Neodiplogastridae), a new record of an entomophilic nematode from Iran. Biologia 68:910-917

18. Kumar S, Stecher G, Tamura K (2016) MEGA7: molecular evolutionary genetics analysis version 7.0 for bigger datasets. Mol Biol Evol 33:1870-1874
19. Ronquist F, Huelsenbeck JP (2003) MrBayes 3: Bayesian phylogenetic inference under mixed models. Bioinformatics 19:1572-1574

20. Darriba D, Taboada GL, Doallo R, Posada D (2012) jModelTest 2: more models, new heuristics and parallel computing. Nat Methods 9:772

21. Rambaut A (2016) Figtree version 1.4.3. http://tree.bio.ed.ac.uk/ software/figtree/

22. Inglis WG (1983) An outline classification on the Phylum Nematoda. Aust J Zool 31:243-255

23. Adamson M (1987) Phylogenetic analysis of the higher classification of the Nematoda. Can J Zool 65:1478-1482

24. Liu GH, Shao R, Li JY, Zhou DH, Li H, Zhu XQ (2013) The complete mitochondrial genomes of three parasitic nematodes of birds: a unique gene order and insights into nematode phylogeny. BMC Genom 21:414

25. Ribas A, de Bellocq JG, Ros A, Ndiaye PI, Miquel J (2013) Morphometrical and genetic comparison of two nematode species: H. spumosa and H. dahomensis (Nematoda, Heterakidae). Acta Parasitol 58:389-398

26. Nadler SA, Carreno RA, Mejía-Madrid H, Ullberg J, Pagan C, Houston R, Hugot JP (2007) Molecular phylogeny of clade III nematodes reveals multiple origins of tissue parasitism. Parasitol 134:1421-1442

27. Skrjabin KI, Schikhobalova NP, Mozgovoi AA (1951) Key to parasitic nematodes, vol II. Oxyurata and Ascaridata. Izdat. Akad. Nauk SSSR, Moscow, p 631 (in Russian)

Publisher's Note Springer Nature remains neutral with regard to jurisdictional claims in published maps and institutional affiliations. 